\title{
Local Adaptive Thresholding Pada Preprocessing Citra Lontar Aksara Bali
}

\author{
Ni Putu Sutramiani, I Ketut Gede Darma Putra, Made Sudarma
}

\begin{abstract}
Balinesse lontar digitalization generates image file which acquired through a scanner or camera. Lontar image has noise because the results of the acquisition of the original lontar contained brown color that exist on the leaves. Therefore this paper focuses on improving the quality of the image to remove noise contained in the image by thresholding process. The method used in this paper is a Local Adaptive Thresholding. The test results in this paper generates the best image with the window $(W)=70$ and the threshold value $(C)=0.05$ which proved to remove noise at most of the few testing that has been done in this paper
\end{abstract}

Index Term - Lontar, scanner, noise, thresholding, local adaptive thresholding.

Abstrak-Digitalisasi lontar menghasilkan file-file citra yang diakuisisi melalui scanner ataupun kamera. Citra lontar tentu saja memiliki noise karena hasil akuisisi pada lontar aslinya terdapat warna kecoklatan yang ada pada daun tersebut. Maka dari itu paper ini berfokus pada peningkatan kualitas citra untuk menghapus noise yang ada pada citra dengan melakukan proses Thresholding. Metode yang digunakan dalam paper ini adalah Local Adaptive Thresholding. Hasil uji coba pada paper ini menghasilkan citra terbaik dengan window $(W)=70$ dan nilai ambang $(C)=0.05$ yang terbukti menghapus noise paling banyak diantara beberapa uji coba yang telah dilakukan pada paper ini

Kata kunci- Lontar, scanner, noise, thresholding, local adaptive thresholding.

\section{Pendahuluan}

$\mathrm{P}$ ELESTARIAN budaya Bali berupa lontar saat ini menjadi perhatian banyak kalangan mulai dari pemerintah dan masyarakat Bali khususnya. Pelestarian ini dapat dilakukan dengan cara digitalisasi lontar. Proses digitalisasi lontar dilakukan dengan menggunakan kamera ataupun scanner. Lontar yang sudah melalui proses digitalisasi tentu saja terdapat noise yang berasal dari serat daun lontar.

Peningkatan kualitas citra merupakan solusi dari permasalahan ini yaitu dengan Thresholding. Thresholding merupakan proses binarisasi citra yang menghasilkan citra biner. Terdapat dua teknik binarisasi yaitu global dan lokal.

Ni Putu Sutramiani adalah Magister Teknik Elektro, Program Pasca Universitas Udayana (e-mail: sutramiani@gmail.com).

I Ketut Gede Darma Putra adalah dengan Magister Teknik Elektro Program Pasca Sarjana Universitas Udayana (e-mail: ikgdarmaputra@gmail.com).

Made Sudarma adalah Magister Teknik Elektro Program Pasca Sarjana Universitas Udayana (e-mail: debronxs@yahoo.co.id).
Global Adaptive Thresholding lebih tepat digunakan dalam citra dengan kontras yang sama pada background dan foreground. Sedangkan pada citra yang memiliki variasi kontras dan pencahayaan sehingga banyak piksel sulit diklasifikasi sebagai background atau foreground lebih tepat menggunakan Local Adaptive Thresholding. Dalam paper ini menggunakan Local Adaptive Thresholding karena citra lontar merupakan citra yang memiliki banyak piksel yang sulit diklasifikasi sebagai sebagai background atau foreground.

Paper serupa sudah pernah ada tentang menghapus noise pada lontar [1]. Paper tersebut memaparkan tentang noise removal dengan cara mengubah citra asli dari lontar menjadi citra biner. Paper lainnya juga tentang teknik binarisasi pada citra [2]. Dalam paper tersebut memaparkan tentang evaluasi beberapa teknik binarisasi pada citra dokumen untuk menemukan kekurangan dalam teknik binarisasi yang sudah ada. Selain itu paper yang membahas tentang teknik Local Adaptive Thresholding dalam Binarisasi terdapat pada paper Singh. T Romen [3], paper ini membahas tentang teknik Local Adaptive Thresholding yang menghilangkan background dengan menggunakan local mean dan mean deviation. Biasanya perhitungan local mean tergantung pada ukuran window.

Berdasarkan paper tersebut, penulis meneliti tentang Preprocessing Citra Aksara Bali Pada Lontar Menggunakan Metode Local Adaptive Thresholding

\section{LANDASAN TEORI}

\section{A. Lontar}

Naskah kuno (manuskrip) adalah warisan kebudayaan nenek moyang yang memiliki nilai yang sangat penting. Naskah kuno banyak terdapat di Indonesia, yang ditulis dengan berbagai macam bahasa dan aksara. Sebagian besar naskah masih tersimpan serta dimiliki oleh masyarakat setempat.

Naskah kuno yang terdapat di Bali adalah Lontar. Lontar bertuliskan aksara Bali dan berisi tentang ajaran-ajaran budaya yang ada di Bali. ajaran-ajaran tersebut seperti mencari hari baik, pengobatan, dan lain sebagainya. Kehidupan masyarakat Bali berpedoman pada ajaran-ajaran yang ada pada lontar tersebut.

Gambar 1. merupakan salah satu lontar yang ada di Bali. Lontar-lontar yang ada di Bali bersifat sakral. Tidak semua orang yang bisa membaca lontar karena aksara-aksara pada lontar sedikit berbeda dengan aksara Bali seperti biasanya 


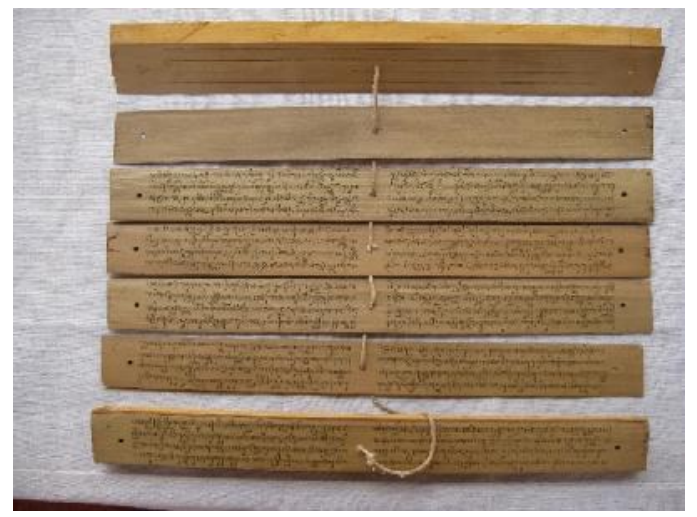

Gambar 1. Lontar Arya Tan Kaur (Ida Pedanda Gde Wayahan Datah, Gria Krotok, Budakeling, Bebandem, Karangasem, Bali)

\section{B. Ejaan Bahasa Bali}

Ejaan Aksara Bali dengan Huruf Latin disesuaikan dengan ejaan pada Bahasa Indonesia [4]. Sesuai dengan keputusan Pasamuhan Agung, dimana Ejaan Aksara itu dibuat sesederhana mungkin.

Berdasarkan aturan di atas, aksara Bali ditulis dengan aturan sebagai berikut:

1. Aksara suara (vokal): a, e, i, u, e. o (enam huruf, taling dan pepet telah diubah).

TABEL I

AKSARA SUARA

\begin{tabular}{|c|c|c|}
\hline Nomor & Aksara Ball & $\begin{array}{l}\text { Ball } \\
\text { Latin }\end{array}$ \\
\hline ไxis & nisulasian\} & $a$ \\
\hline 121 & $\ln 3$ & ê \\
\hline 121 & 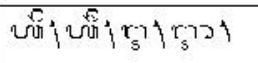 & i \\
\hline$|s|$ & ज्gा w 121201 & $\mathrm{u}$ \\
\hline $199 ?$ & 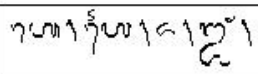 & e \\
\hline 101 & $n+\pi>10+5=1$ & 0 \\
\hline
\end{tabular}

Kalau huruf-huruf Bali dalam hal ini adalah Aksara Suara, yang saat ini dituliskan sesuai dengan tulisan Bali Latin seperti di bawah ini:

Keterangan :

a. Wisarga ha penulisannya sama seperti ä kara.

b. Suara dirga penulisannya sama seperti aksara hrasua (pendek)

c. Pepet dan taling penulisannya sama

d. Bentuk aksara suara rangkap: ai / ia $=\mathrm{e}$ (taling) dan au / ua $=$ o

Para ahli menyatakan bahwa penulisan kata dengan wisarga ha umumnya merupakan kata-kata yang berasal dari Bali, namun penulisan kata dengan a kara merupakan kata yang berasal dari Jawa Kuna atau Sanskerta. Berdasarkan hal tersebut, maka:
TABEL II

PERgantian AKSARa SuARA

\begin{tabular}{|c|c|}
\hline Aksara Suara & Diganti dengan \\
\hline SA & $\mathrm{sin}$ \\
\hline$r_{s}$ & 20 \\
\hline 2 & $2 \pi$ \\
\hline$\therefore$ & 7) \\
\hline 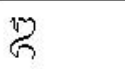 & 7us \\
\hline
\end{tabular}

2. Aksara wianjana (konsonan) yang digunakan adalah : h, n, c, r, k, g, t, m, ng, b, s, w, l, p, d, j, y, ny, (18 huruf).

TABEL III

AKSARA WIANJANA (KONSONAN)

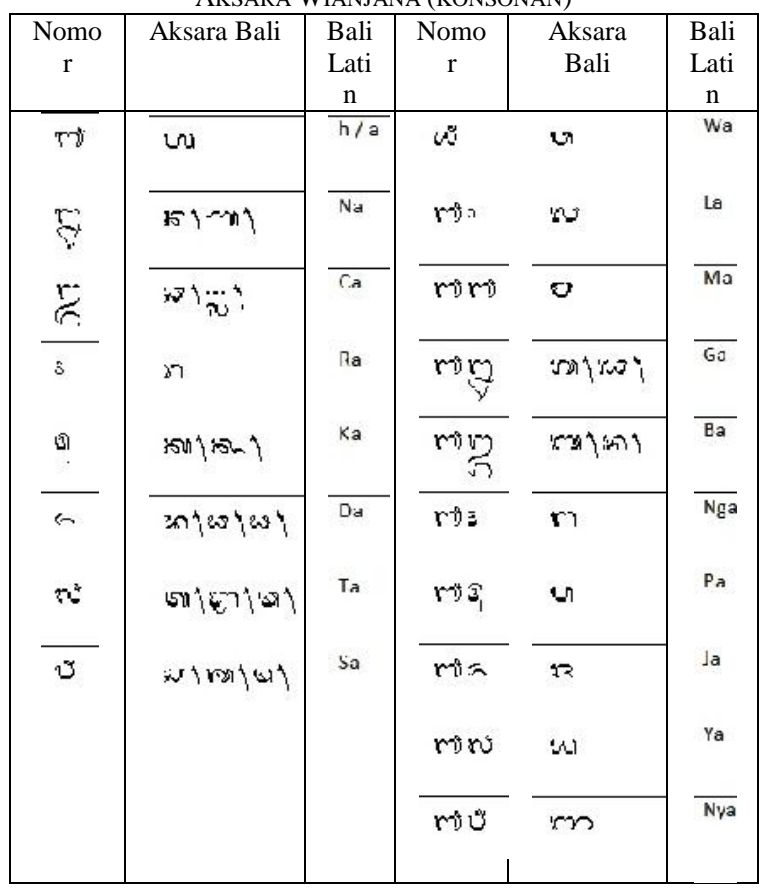

TABEL IV

\begin{tabular}{|c|c|c|}
\hline \multicolumn{3}{|c|}{ PENULISAN AKSARA WIANJANA } \\
\hline Aksara & Keterangan & Istilah Aksara \\
\hline $\operatorname{mos}$ & na rambat & murdania \\
\hline$\ddot{a}^{\prime}$ & ca laca & talawia mahaprana \\
\hline 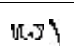 & ga gora & kantia mahaprana \\
\hline (5) & ta tawa & dantia mahaprana \\
\hline$(1)$ & ta latik & Murdania \\
\hline$\times 1 ?$ & ba kembang & ostia mahaprana \\
\hline (s) & sa sapa & Murdania \\
\hline ron & sa saga & Talawia \\
\hline บ) & pa kapal & ostia mahaprana \\
\hline w) & da madu & dantia mahaprana \\
\hline
\end{tabular}


29 dibaca da madu, merupakan Aksara Bali yang tidak memiliki bentuk tersendiri, lain halnya pada aksara yang terdapat di Jawa, contohnya pada Aksara Jawa Kuna Latin. Istilah dantia dan murdania yang merupakan penamaan aksara wianjana dinyatakan kurang tepat. Istilah yang sesuai harus menggunakan nama umum. Selain itu, pakadangan aksara atau daerah artikulasi perlu digunakan dalam penamaan aksara.

\section{Pengangge}

Istilah Pengangge pada penulisan aksara Bali adalah sebuah simbol yang tidak bisa berdiri sendiri karena penulisan Aksara Pengangge ini harus bersama dengan suatu aksara wianjana dengan melekati aksara wianjana atau aksara suara. Penulisan aksara Pengangge akan mempengaruhi cara membaca aksara Bali dan juga cara menulisnya. Pada Aksara Bali, terdapat tiga jenis pangangge, yaitu pangangge tengenan, pangangge suara, dan pangangge aksara.

\section{Local Adaptive Thresholding}

Proses thresholding atau disebut juga pengambangan ini menghasilkan sebuah citra yang mempunyai dua nilai pada tingkat keabuan, hitam dan putih yang disebut dengan biner [5]. Proses pengambangan citra grayscale untuk menghasilkan citra biner secara umum adalah sebagai berikut.

$$
G(x, y)=\left\{\begin{array}{l}
1 \text { if } f(x, y) \geq T \\
0 \text { if } f(x, y)<T
\end{array}\right\}
$$

$G(x, y)$ menyatakan citra biner dari grayscale $f(x, y), T$ menyatakan nilai ambang (threshold). Nilai $\mathrm{T}$ memiliki peranan yang sangat penting pada proses thresholding dan sangat mempengaruhi kualitas citra biner yang dihasilkan.

Metode thresholding yang digunakan pada paper ini adalah local Adaptive Thresholding. Pada metode local Adaptive Thresholding ini, nilai ambang lokal dapat dihitung dengan salah satu dari tiga cara yaitu :

$$
T=\frac{\Sigma_{(x, y)} \sum_{\in W} f(x, y)}{N_{W}}-C,
$$

atau

$$
\begin{gathered}
T=\text { median }\{f(x, y),(x, y) \in W\} \\
T=\frac{\max \{f(x, y),(x, y) \in W\}+\min \{f(x, y),(x, y) \in W\}}{2}
\end{gathered}
$$

dimana,

- W merupakan blok yang diproses,

- NW merupakan jumlah piksel pada setiap blok W,

- C merupakan konstanta yang dapat ditentukan secara bebas. Bila $\mathrm{C}=0$, berarti nilai ambang sama dengan nilai rata-rata setiap piksel pada blok bersangkutan.

Ketiga cara di atas berturut-turut menghitung nilai $\mathrm{T}$ dengan menghitung nilai rata-rata, median, dan rata-rata nilai maksimum dan minimum dari piksel di dalam window.

\section{Metodelogi}

\section{A. Akuisisi Citra}

Akuisisi data merupakan proses pengambilan data dari data analog ke digital yaitu dari lontar menjadi citra lontar dengan menggunakan scanner. Citra yang disimpan akan diproses pada tahapan preprocessing. Tahapan ini diawali dengan meminjam salah satu lontar yaitu Lontar Wariga Palalubangan di Perpustakaan Program Pascasarjana Institut Hindu Dharma Negeri Denpasar. Untuk memproses ketahapan selajutnya (preprocessing), maka diperlukan lontar dalam bentuk file citra lontar. Maka dari itu digunakan scanner untuk proses pengambilan citra dari lontar tersebut. Setelah mendapatkan hasil citra lontar.

\section{B. Preprocessing}

Preprocessing merupakan tahapan untuk meningkatkan kualitas citra, menghilangkan noise yang ada pada citra, maupun menentukan bagian citra yang akan digunakan dalam tahapan selanjutnya. Dalam paper ini, teknik yang digunakan adalah binarisasi citra dengan menggunakan Local Adptive Thresholding.

Binarisasi citra merupakan proses mengubah nilai piksel menjadi dua kelompok yaitu putih untuk background dan hitam untuk foreground. Teknik binarisasi yang digunakan adalah Local Adptive Thresholding karena pada citra lontar banyak piksel yang sulit ditentukan yang mana background ataupun foreground.

Metode local Adaptive Thresholding merupakan metode thresholding dengan menghitung nilai ambang lokal. Nilai ambang dapat dihitung dengan salah satu dari tiga cara yaitu dengan menggunakan rumus (2.2), (2.3), (2.4). Ketiga rumus ini berturut-turut menghitung nilai $\mathrm{T}$ dengan menghitung nilai rata-rata, median, dan rata-rata nilai maksimum dan minimum dari piksel di dalam window.

\section{Hasil Dan Pembahasan}

\section{A. Hasil}

Hasil dari proses preprocessing menggunakan metode Local Adaptive Thresholding dari citra lontar asli dan menghasilkan citra hasil preprocessing. Perbedaan antara hasil dengan citra hasil bisa dilihat pada gambar berikut.

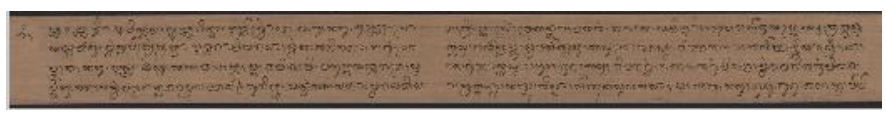

Gambar 2. Citra Asli

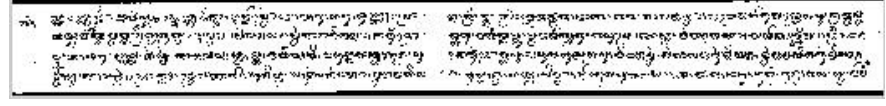

Citra Hasil Preprocessing

\section{B. Pembahasan}

Preprocessing menggunakan Local Adaptive Thresholding merupakan proses perbaikan kualitas citra dengan cara dithresholding sehingga menghasilkan citra biner. Pada proses thresholding, W (window) menyatakan blok yang diproses dan 
C (nilai ambang) menyatakan suatu konstanta yang dapat ditentukan secara bebas. Pada paper ini dilakukan 5 kali thresholding dengan window dan nilai ambang yang berbeda. Hasil dari percobaan bisa dilihat pada tabel di berikut ini.

TABEL IV

HASIL THRESHOLDING

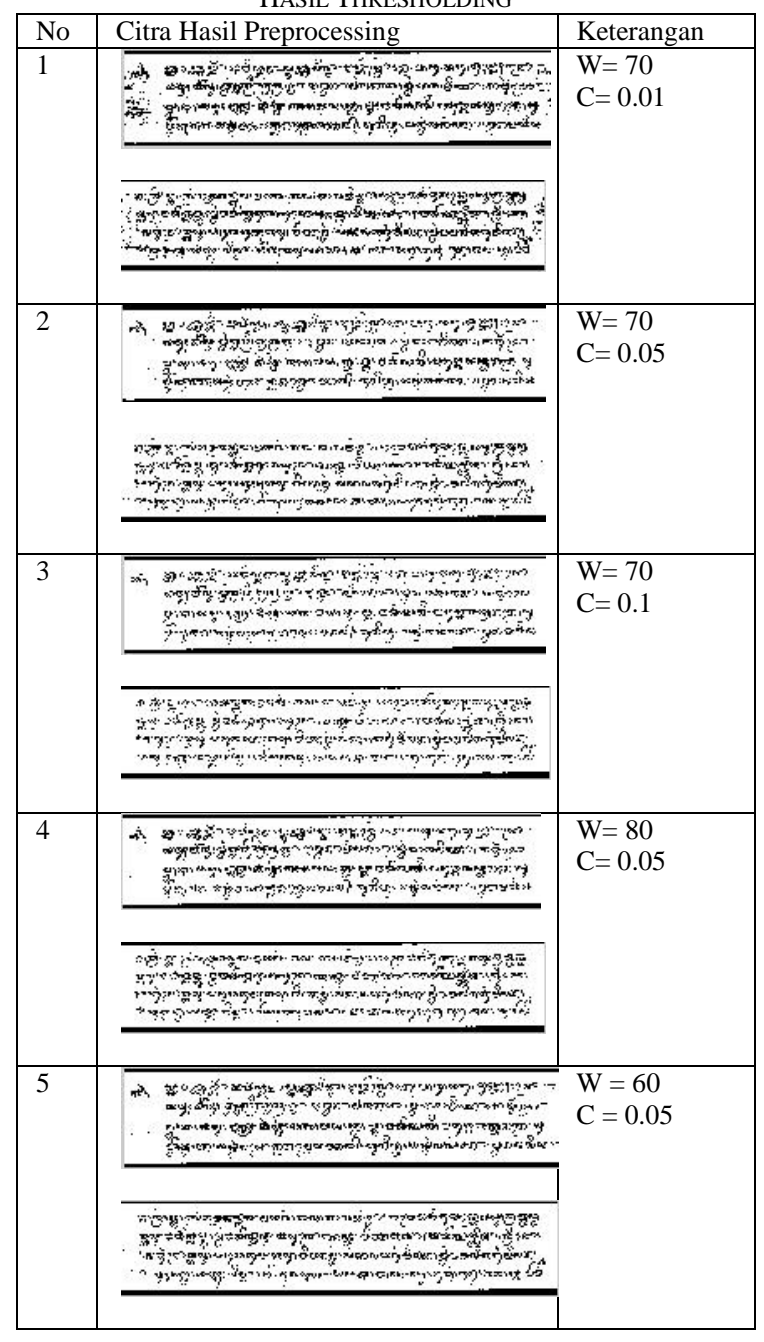

Dari hasil uji coba di atas maka didapat hasil yang paling sedikit terdapat noise yaitu dengan menetukan nilai $\mathrm{W}=70$ dan $\mathrm{C}=0.05$ yang dapat dilihat pada kolom nomor 2 . Sebagai pembanding ada 4 hasil yang mendekati dapat dilihat pada tabel di atas.

\section{KeSIMPULAN}

Paper ini telah memaparkan penerapan metode Local Adaptive Thresholding untuk preprocessing pada lontar Bali. Berdasarkan uji coba paper ini menyimpulkan bahwa window $(\mathrm{W})=70$ dan nilai ambang $(C)=0.05$ mendapatkan hasil yang paling maksimal karena paling banyak noise yang terhapus dalam satu citra dibandingkan percobaan lainnya yang masih nampak noise-noise yang ada pada citra.

\section{DAFTAR PUSTAKA}

[1] Prapitasari. Luh Putu Ayu, Noise Removal for Ancient Palm Leaf Manuscript of Bali, Konferensi Nasional Sistem Informasi (KNSI) No ISBN 9786029876802,2012

[2] Gill. Tarjot Kaur, Document Image Binarization Tecniques-A Review, International journal of Computer Applications (0975 - 8887), Volume 98-No.12, July 2014

[3] Singh. T Romen, A New Local Adaptive Thresholding Technique in Binarization, International Journal of Computer Science Issues (IJCSI), Volume 8, Issue 6, No 2, Nopember 2011, ISSN 1694-0814

[4] http://www.babadbali.com/aksarabali/books/ppebb.htm

[5] Putra. IKG Darma, Pengolahan Citra Digital, Andi No ISBN 9789792914436, 2010 